\title{
XRCC1 Arg194Trp polymorphism, risk of nonmelanoma skin cancer and extramammary Paget's disease in a Japanese population
}

\author{
Koji Chiyomaru $\cdot$ Tohru Nagano $\cdot$ Chikako Nishigori
}

Received: 2 November 2011/Revised: 9 May 2012/Accepted: 11 May 2012 / Published online: 26 May 2012

(C) The Author(s) 2012. This article is published with open access at Springerlink.com

\begin{abstract}
The X-ray repair cross-complementing groups 1 gene plays an important role in base excision repair. At least three common single nucleotide polymorphisms frequently occur in this gene (Arg399Gln, Arg194Trp and Arg280His). Recent studies reported that these polymorphisms were associated with not only risk of visceral malignancy but also that of skin cancer such as basal cell carcinoma and squamous cell carcinoma, whereas the results of previous study vary among races. In this casecontrol study, we investigated whether these single nucleotide polymorphisms were associated with the risk of skin cancer in a Japanese population. The study population was composed of 197 patients with skin cancer (27 actinic keratoses, 47 basal cell carcinomas, 27 squamous cell carcinomas, 29 Bowen's diseases, 46 malignant melanomas and 21 extramammary Paget's diseases) and 93 control subjects. We genotyped two single nucleotide polymorphisms (Arg194Trp and Arg399Gln) using polymerase chain reaction-restriction fragments length polymorphism analysis. We found a significantly increased risk for basal cell carcinoma, squamous cell carcinoma and extramammary Paget's disease associated with Arg194Trp [adjusted odds ratio $(\mathrm{AOR})=2.347,3.587,3.741,95 \%$ confidence interval (CI) 1.02-5.39, 1.19-10.8, 1.15-12.2, respectively]. We also found a significantly decreased risk for basal cell carcinoma associated with Gln399Gln (AOR $=0.259,95 \%$ CI 0.07-0.96). Our data suggest that
\end{abstract}

K. Chiyomaru $(\bowtie) \cdot$ T. Nagano · C. Nishigori Division of Dermatology, Department of Internal Related, Kobe University Graduate School of Medicine, 7-5-2 Kusunoki-cho, Chuo-ku, Kobe 650-0017, Japan e-mail: chiyomaru@s2.dion.ne.jp the Arg194Trp polymorphism could be associated with nonmelanoma skin cancer and extramammary Paget's disease risk in a Japanese population.

Keywords Skin cancer $\cdot$ SNP $\cdot$ XRCC1

\section{Introduction}

"Early detection, rapid cure" is most effective strategy for cancer treatment. The outcome from educational campaigns by oncologists has not been enough for reducing the number of patients with advanced cancer. Furthermore, the cost of medical expense is growing with each passing year. Detection of high risk population for cancer seems to become a practical way for educating people. For example, detecting a DNA variation associated with cancer susceptibility of each individual could become an effective strategy for solving the problem.

Cancers are not single-gene diseases. Many oncogenes, tumor suppressor genes and DNA repair genes are all likely to be involved. DNA in most cells is regularly damaged by endogenous and exogenous mutagens. Unrepaired damage can result in apoptosis or may lead to unregulated cell growth and cancer. Inheritance of genetic variants at one or more loci results in reduced DNA repair capacity. DNA repair enzymes have been reported to play an important role in the carcinogenesis of several cancers. DNA repair enzymes are involved in repairing damaged DNA and at least four pathways operate on specific types of DNA damage: the base excision repair (BER), nucleotide excision repair (NER), double strand break repair (DSBR) and mismatch repair (MMR) pathways. Enzymes involved in BER include XRCC1, those involved in NER include XPC, $\mathrm{XPD}$ and ERCC1, those involved in DSBR include 
BRCA1, BRCA2 and XRCC3, and those involved in MMR include MLH1, MSH2, PMS2 and MSH6 [9].

From this standpoint, we focused on single nucleotide polymorphisms (SNPs) of the DNA repair gene, X-ray repair cross-complementing groups 1 (XRCC1) which was the first identified human gene involved in the repair of single strand break (SSB) of DNA formed by exposure to ionizing radiation and alkylating agents [20]. The SNPs may alter the function and capacity of DNA repair. Although enzymatic activity has not been revealed yet, $X R C C 1$ interacts with many proteins involved in base excision repair (BER) and $\mathrm{SSB}$ repair. It has been supposed that $X R C C 1$ plays a role as a scaffold protein for coordinating and facilitating the various DNA repair pathways $[11,13]$. The SNPs of XRCC1 has been associated with a risk factor of cancers such as lung cancer [3], breast cancer [15], prostate cancer [7, 19], and also with skin cancers $[6,9,17]$.

In the case of skin cancer, most people can see the lesion by his or her own eyes. So the information about his/her susceptibility to skin cancer enables him/her to realize "Early detection and rapid cure".

On the other hand, a contribution of SNPs to skin cancer has ethnic and racial differences. In that way, further insight into each society is important.

In the present study, we investigated the association between polymorphisms of $X R C C 1$ and skin cancer in a Japanese population.

\section{Materials and methods}

Study population

One-hundred and ninety-seven patients (mean age \pm standard deviation (SD), $72.9 \pm 12.2$ years; age range 35-95 years) with skin cancer [27 actinic keratoses (AK), 47 basal cell carcinomas (BCC), 27 squamous cell carcinomas (SCC), 29 Bowen's disease (BD), 46 malignant melanomas (MM) and 21 extramammary Paget's diseases (EPD)] and 93 control subjects (mean age \pm SD, $66.1 \pm 13.7$ years; age range 28-89) who visited the dermatology clinic in Kobe University Hospital between April
2004 and November 2010 were enrolled in this study. Clinical diagnosis was confirmed by histopathological analysis in all cases.

We subcategorized the patients according to the location of cancer lesions whether on sun exposure site (head, neck and hand) or not. The frequencies of BCC were: sun exposure site, $89.4 \%$ and not sun exposure site, $10.6 \%$. Those of SCC were: sun exposure site, $51.9 \%$ and not sun exposure site, $48.1 \%$. Those of MM were: sun exposure site, $17.4 \%$ and not sun exposure site, $82.6 \%$.

The control group consists of 93 age- and sex-matched non-affected unrelated Japanese individuals from the same area in Japan with minor fungi, bacterial infections or seborrheic keratosis. We excluded the patients with other malignant disorders (Table 1).

We handled these patients as anonymous samples about which nobody could know their personal information other than their genotypes. Written informed consent was also obtained from all participants. The Medical Ethics Committee of Kobe University approved this work that was conducted in accordance with the Declaration of Helsinki principles.

\section{Genetics analysis}

Genomic DNA was extracted from peripheral blood using Qiagen FlexiGene DNA kit. The nucleotide changes were determined by polymerase chain reaction-restriction fragments length polymorphism (PCR-RFLP) analysis using the isolated genomic DNA as a template. PCR for the XRCC1 Arg194Trp (C > T) polymorphism was carried out using primers 5' GCC CCG TCC CAG GTA 3' and 5' AGC CCC AAG ACC CTT TCA CT $3^{\prime}$. DNA was amplified for 35 cycles comprising denaturing at $94^{\circ} \mathrm{C}$ for $60 \mathrm{~s}$, annealing at $61^{\circ} \mathrm{C}$ for $60 \mathrm{~s}$ and extension at $72^{\circ} \mathrm{C}$ for $60 \mathrm{~s}$. The PCR products were detected after incubation with the restriction endonuclease $P v u \mathrm{II}$ at $37^{\circ} \mathrm{C}$ for $2 \mathrm{~h}$.

The forward and reverse primers for the XRCC1 Arg399Gln ( $\mathrm{G}>\mathrm{A}$ ) polymorphism used were $5^{\prime} \mathrm{CCC}$ CAA GTA CAG CCA GGT C $3^{\prime}$ and $5^{\prime}$ TGT CCC GCT CCT CTC AGT AG $3^{\prime}$, respectively. PCRs were run for 35 cycles: $94^{\circ} \mathrm{C}$ for $60 \mathrm{~s}, 62^{\circ} \mathrm{C}$ for $60 \mathrm{~s}, 72^{\circ} \mathrm{C}$ for $60 \mathrm{~s}$, and

Table 1 Clinical characteristics and numbers among cases and controls

\begin{tabular}{|c|c|c|c|c|c|c|c|}
\hline Characteristics & $\begin{array}{l}\text { Cases (with AK } \\
\text { diagnosis), No. } \\
(\%)(n=27)\end{array}$ & $\begin{array}{l}\text { Cases (with } \\
\text { BCC diagnosis), } \\
\text { No. (\%) } \\
(n=47)\end{array}$ & $\begin{array}{l}\text { Cases (with SCC } \\
\text { diagnosis), No. } \\
(\%)(n=27)\end{array}$ & $\begin{array}{l}\text { Cases (with BD } \\
\text { diagnosis), No. } \\
(\%)(n=29)\end{array}$ & $\begin{array}{l}\text { Cases (with MM } \\
\text { diagnosis), No. } \\
(\%)(n=46)\end{array}$ & $\begin{array}{l}\text { Cases (with EPD } \\
\text { diagnosis), No. } \\
(\%)(n=21)\end{array}$ & $\begin{array}{l}\text { Controls, } \\
\text { No. }(\%) \\
(n=93)\end{array}$ \\
\hline Men & $8(29.6)$ & $25(53.2)$ & $14(51.9)$ & $11(37.9)$ & $24(52.2)$ & $11(52.4)$ & 48 (51.6) \\
\hline Women & $19(70.4)$ & $22(46.8)$ & $13(48.1)$ & $18(62.1)$ & $22(47.8)$ & $10(47.6)$ & 45 (48.4) \\
\hline
\end{tabular}

$A K$ actinic keratosis, $B D$ bowen's disease, $B C C$ basal cell carcinoma, $S C C$ squamous cell carcinoma, $M M$ malignant melanoma, $E P D$ extramammary Paget's disease 
products were digested with the restriction endonuclease MspI at $37^{\circ} \mathrm{C}$ for $2 \mathrm{~h}$.

Statistical analysis

For statistical analysis, we used SPSS for Windows, version 17.0 (SPSS Japan Inc.) to calculate the crude odds ratio (OR), the adjusted odds ratio (AOR) and $95 \%$ confidence interval (CI). All adjusted models included age and sex.

\section{Results}

Polymorphisms of XRCC1 codons 194 and 399 and skin cancer risk

The XRCC1 gene polymorphisms Arg194Trp and Arg399 Gln were investigated. Their genotype distributions in skin cancers and controls are shown in Table 2. We found a significantly increased risk for skin cancers associated with $\operatorname{Arg} 194 \operatorname{Trp}(\mathrm{AOR}=1.810,95 \%$ CI 1.03-3.18).

Polymorphisms of XRCC1 codons 194 and 399 and each category of skin cancer risk

We investigated the XRCCl gene polymorphisms of codon 194 and 399 in the each skin cancer (Table 3). We found a significantly increased risk for BCC, SCC and EPD associated with Arg194Trp (AOR = 2.347, 3.587, 3.741, $95 \%$ CI 1.02-5.39, 1.19-10.8, 1.15-12.2, respectively). We also found a significantly decreased risk for BCC associated with Gln399Gln (AOR $=0.259,95 \%$ CI 0.07-0.96).

Polymorphisms of XRCC1 codons 194 and 399 and nonmelanoma skin cancer (NMSC) risk

Next we analyzed relationship between XRCC1 SNP and NMSC (BCC and SCC) (Table 2). We found a significantly increased risk for NMSC associated with Arg194Trp $(\mathrm{AOR}=2.380,95 \%$ CI 1.15-4.95). We found a significantly decreased risk for NMSC associated with Gln399 Gln $(\mathrm{AOR}=0.318,95 \%$ CI 0.11-0.92).

\section{Discussion}

In our present study, although our statistical analysis of each skin cancer and controls had potential biases, a significantly increased risk for skin cancer was associated with the SNP of XRCC1 Arg194Trp (AOR = 1.810, $95 \%$ CI 1.03-318) (Table 2). Two studies [6,9] reported an

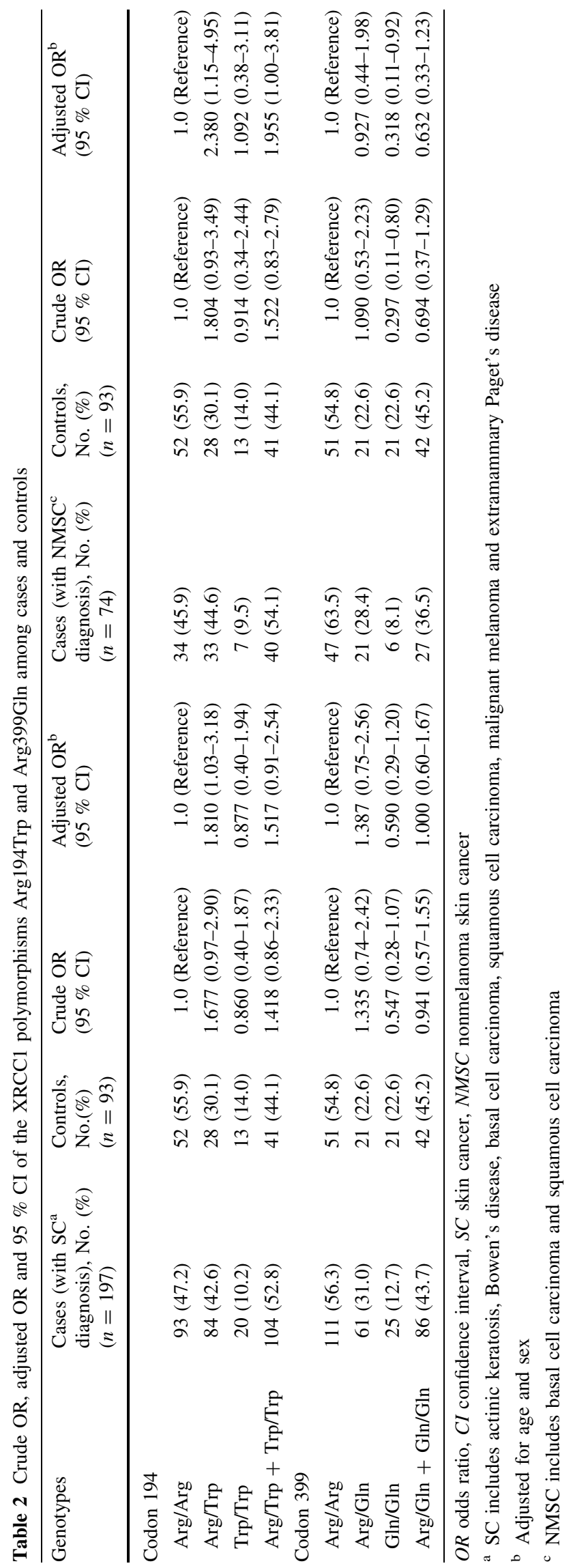




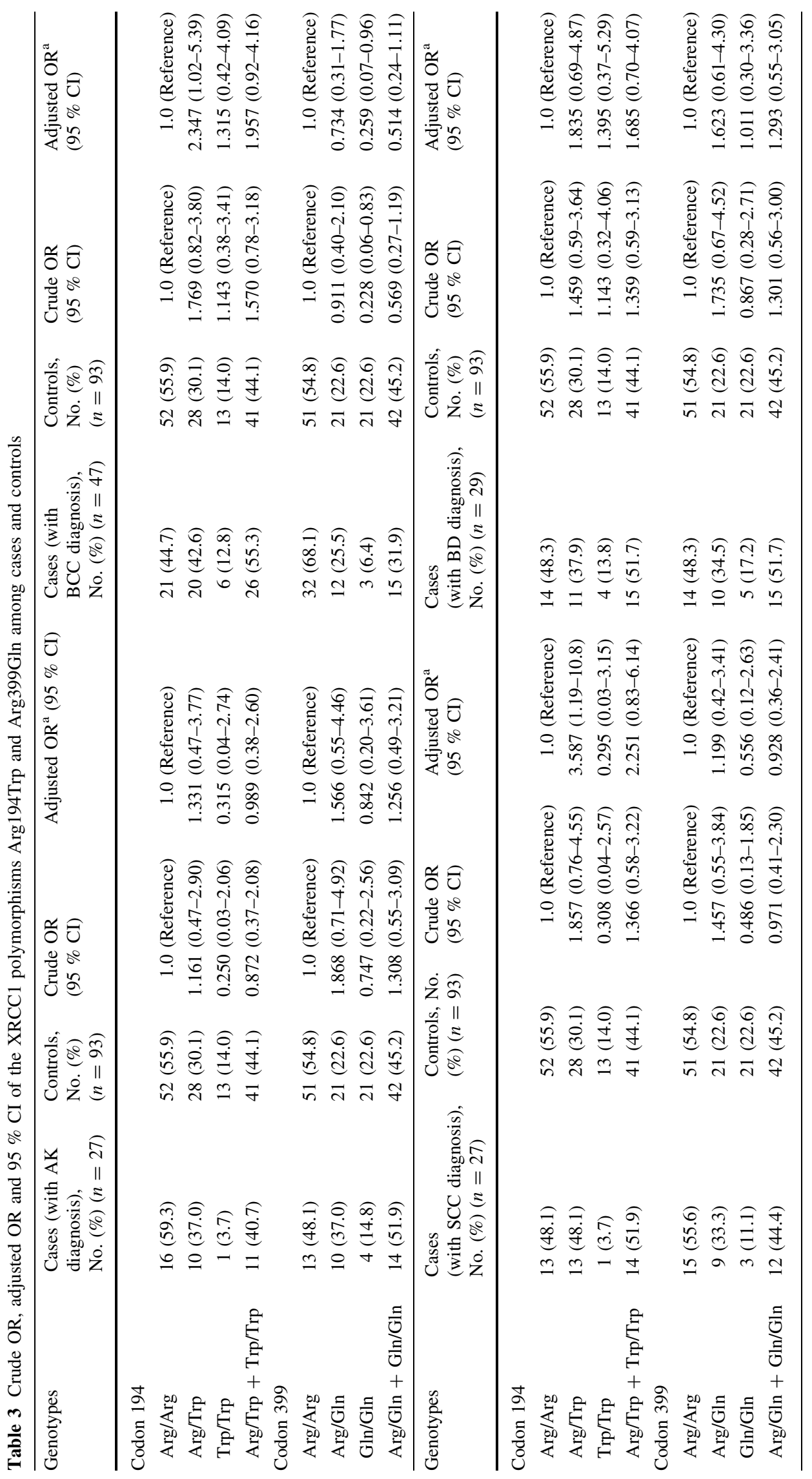




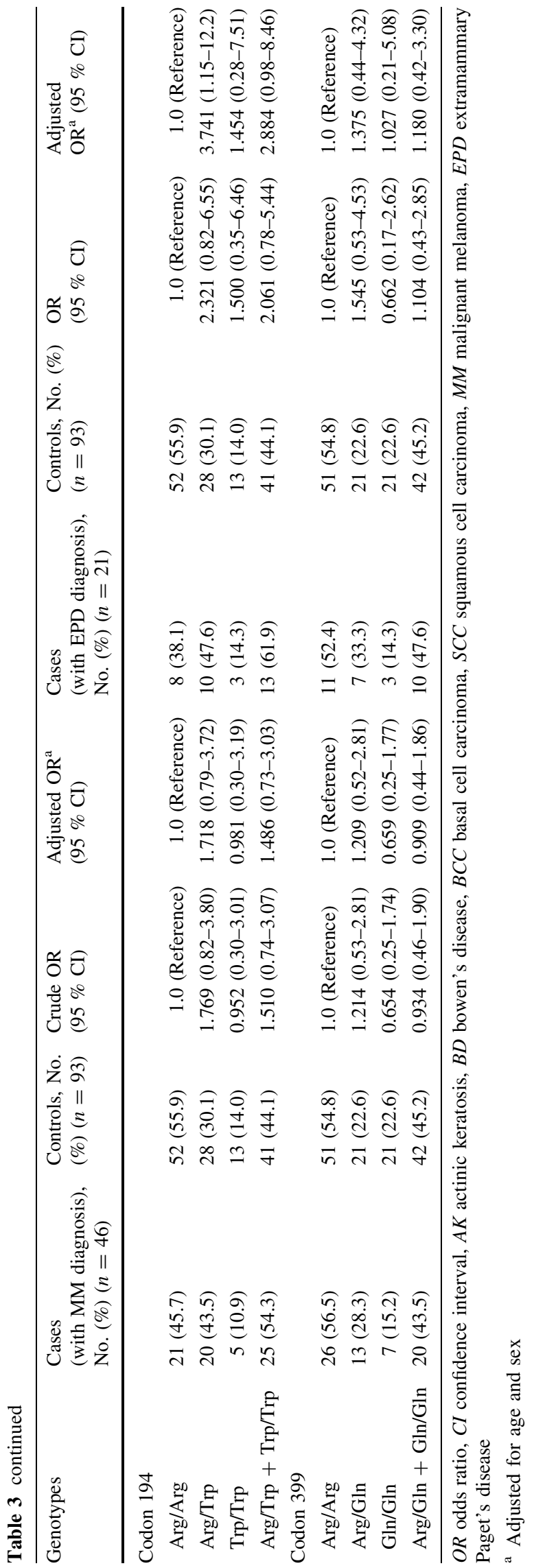

association of risk in skin cancer with XRCC1 Arg194Trp, but the results were controversial. Han et al. reported the increased risk of SCC with Arg194Trp, on the other hand, Kang et al. reported the decreased risk of SCC with the same SNP. These results indicate that the risk of skin cancer in SNP in XRCCl varies among races. In our present study, the polymorphism of XRCC1 Arg194Trp has been shown to be an important factor in susceptibility to skin cancer among Japanese population.

Association of XRCC1 Arg194Trp could be not only with MNSC but also with EPD (Tables 2, 3). Although the number of each skin cancer has still been small, the polymorphisms of XRCC1 Arg194Trp could be involved in carcinogenesis of BCC and SCC. On the other hand, in the case of AK and BD, XRCCl Arg194Trp has no statistical significance, which indicates XRCC1 Arg194Trp would be related to susceptibility to not in situ but advanced skin cancer. In addition, actinic keratosis usually heralds SCC. Many of SCC cases should also have AKs, thus, it could be a useful indicator for the progression of the disease. Little is known about the molecular mechanisms or genetic disorder of pathogenesis of EPD. It was reported that there were high expressions of c-erb B2 and PIG7/LITAF in EPD [12, 18], and Ki-67 and cycline D1 in invasive EPD [1]. There is no report investigating the XRCC1 Arg194Trp polymorphism in EPD. Since EPD occurs in sun-protected areas, the true meaning of the SNPs in our patients needs to be analyzed in a larger number of patients and in relation to other genetic aberrations. As far as we know, our result is a new indication for the relationship between polymorphism of XRCCl and EPD.

In the analysis of NMSC on the polymorphisms of $X R C C 1$, we found a significantly increased risk with Arg194Trp (AOR $=2.380,95 \%$ CI 1.15-4.95) and also decreased risk with Gln399Gln (AOR $=0.318,95 \% \mathrm{CI}$ 0.11-0.92). Previous reports showed that XRCC1 Gln399Gln homozygote variant was associated with a significantly reduced risk of NMSC [17], which supported our results.

The inverse association of different loci (codon 194 and 399) of XRCCl has been observed in previous reports $[6,9]$. The reason for this still remains unknown, several factors relevant to this polymorphism, such as different populations, different skin types [4] and differently damaged levels of apoptotic mechanisms, might cause different outcomes. Our data suggest that the Arg194Trp and Arg399Gln polymorphisms may be differently associated with NMSC in a Japanese population.

In the case of skin carcinogenesis, ultraviolet (UV) plays an important role [5], especially in the induction of mutations in both oncogenes and tumor suppressor genes [2, 8]. It has been reported that UV has been implicated in inhibition of anti-tumor T-cell immune response through elevated interleukin 10 (IL-10) and other cytokines level [21]. 


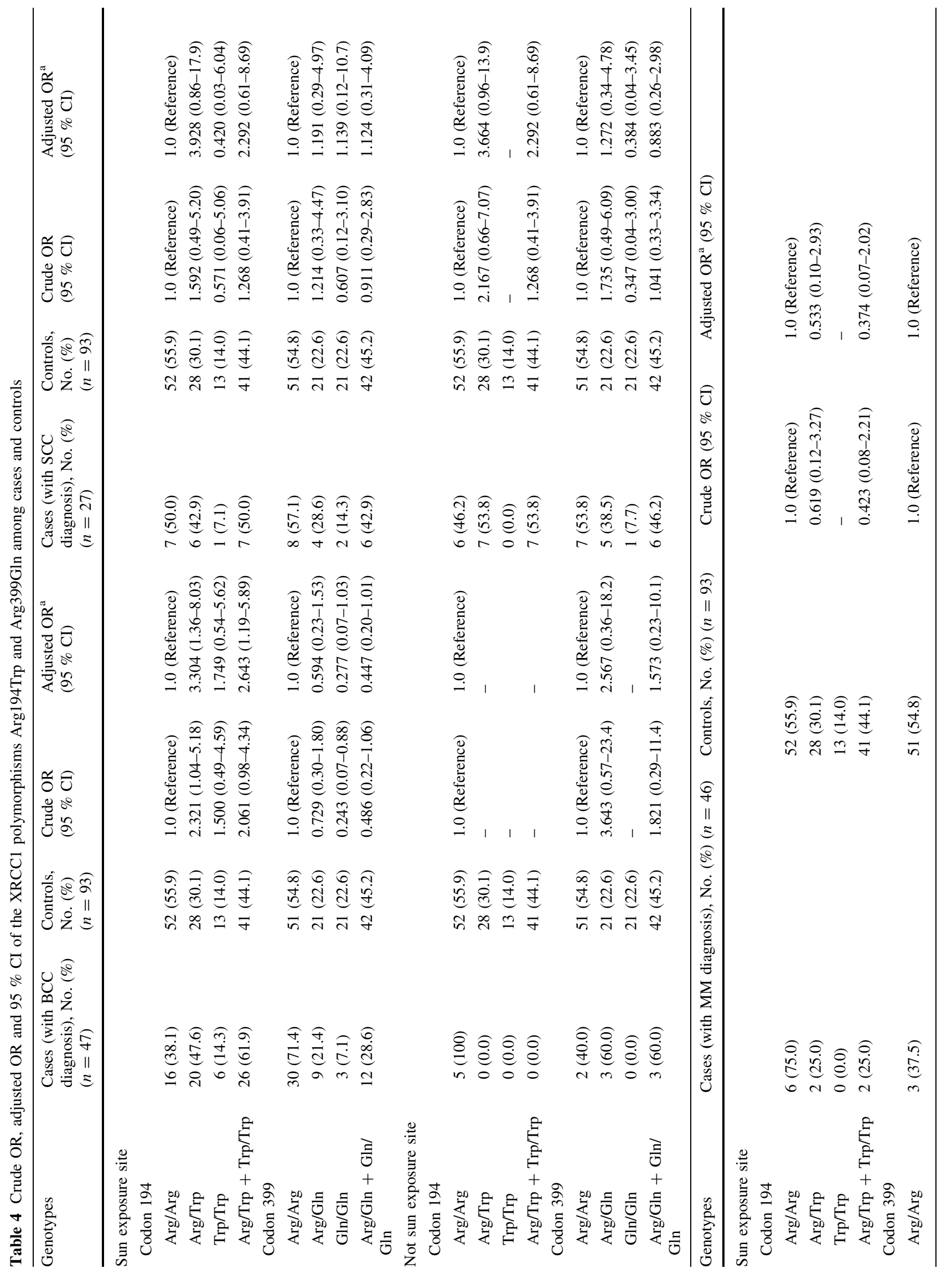




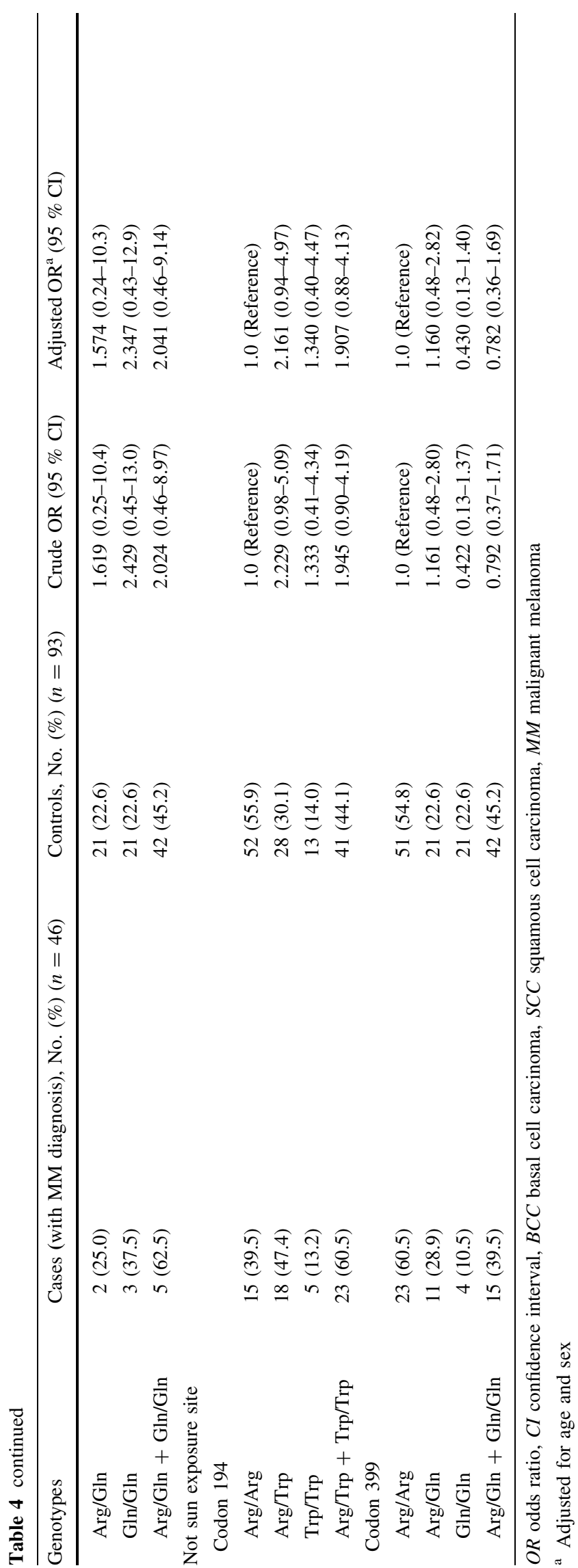

Recently, we have shown that IL-10 polymorphisms are strongly correlated to sun-related skin cancers in a Japanese population [16]. Therefore, we thought that under the circumstances without UV effects, BER deficiency could be more involved in carcinogenesis in the skin. However, further analysis of our data indicated that polymorphism of XRCC1 codon 399 and 194 revealed much more significantly increased risk for BCC on sun-exposed area associated with Arg194Trp and Arg194Trp + Trp194 $\operatorname{Trp}(\mathrm{AOR}=3.304,95 \%$ CI $1.36-8.03$ and $\mathrm{AOR}=$ $2.643,95 \%$ CI 1.19-5.89, respectively) (Table 4). Although the case numbers are low in this study and thus, the statistical power is low, our results indicate a possibility of association of the polymorphism of $X R C C l$ with UV-induced carcinogenesis. Actually, Moser et al. [14] indicated the association of XRCCl with not only BER but also with nucleotide excision repair pathway which has a major role in repairing UV-induced DNA damage.

The functional significance of SNPs is still largely unknown. Recent reports show that the SNPs of XRCC1 have been focused on not only in silico analysis but also on in vitro and in vivo [10]. Further functional analyses of the SNPs are needed.

Being different from visceral cancers, almost all skin cancers are visible. Thus, early detection of skin anomaly should be possible for not only medical doctors but also for each individual. Nevertheless, there are still many patients with advanced skin cancer. Thus, screening of skin cancer risk for each individual enables them to know the importance of careful examination on their own skin in their daily life, leading to reduction in both the number of patients with advanced skin cancer and the cost of medical expense.

In conclusion, $X R C C 1$ gene polymorphisms, the Arg 194Trp genotype increased the risk of NMSC and EPD in a Japanese population. Consequently, this genotype could be used as biomarkers for the estimation of skin cancer risk, leading to education to the public, enabling the risk-individuals to obtain "Early detection and rapid cure".

Acknowledgments This study was partially supported by a grant from Global Center of Excellence for Education and Research on Signal Transduction Medicine in the Coming Generation.

Open Access This article is distributed under the terms of the Creative Commons Attribution License which permits any use, distribution, and reproduction in any medium, provided the original author(s) and the source are credited.

\section{References}

1. Aoyagi S, Akiyama M, Shimizu H (2008) High expression of Ki-67 and cyclin D1 in invasive extramammary Paget's disease. J Dermatol Sci 50:177-184 
2. Brash DE, Rudolph JA, Simon JA, Lin A, McKenna GJ, Baden HP et al (1991) A role for sunlight in skin cancer: UV-induced p53 mutations in squamous cell carcinoma. Proc Natl Acad Sci USA 88:10124-10128

3. Chen S, Tang D, Xue K, Xu L, Ma G, Hsu Y et al (2002) DNA repair gene XRCC1 and XPD polymorphisms and risk of lung cancer in a Chinese population. Carcinogenesis 23:1321-1325

4. Gao R, Price DK, Sissung T, Reed E, Figg WD (2008) Ethnic disparities in Americans of European descent versus Americans of African descent related to polymorphic ERCC1, XRCC1, and PARP1. Mol Cancer Ther 7:1246-1250

5. Han J, Graham A, Hunter DJ (2006) Risk factors for skin cancers: a nested case-control study within the Nurses' health study. Int J Epidemiol 35:1514-1521

6. Han J, Hankinson SE, Colditz GA, Hunter DJ (2004) Genetic variation in XRCC1, sun exposure, and risk of skin cancer. $\mathrm{Br}$ J Cancer 91:1604-1609

7. Hirata H, Hinoda Y, Tanaka Y, Okayama N, Suehiro Y, Kawamoto K et al (2007) Polymorphisms of DNA repair genes are risk factors for prostate cancer. Eur J Cancer 43:231-237

8. Ishizaki K, Tsujimura $T$, Nakai M, Nishigori C, Sato K, Katayama $S$ et al (1992) Infrequent mutation of the ras genes in skin tumors of xeroderma pigmentosum patients in Japan. Int $\mathbf{J}$ Cancer 50:382-385

9. Kang SY, Lee KG, Lee W, Shim JY, Ji SI, Chung KW et al (2007) Polymorphisms in the DNA repair gene XRCC1 associated with basal cell carcinoma and squamous cell carcinoma of the skin in a Korean population. Cancer Sci 98:716-720

10. Ladiges WC (2006) Mouse models of XRCC1 DNA repair polymorphisms and cancer. Oncogene 25:1612-1619

11. Mani RS, Fanta M, Karimi-Busheri F, Silver E, Virgen CA, Caldecott KW et al (2007) XRCC1 stimulates polynucleotide kinase by enhancing its damage discrimination and displacement from DNA repair intermediates. J Biol Chem 282: 28004-28013

12. Matsumura $Y$, Matsumura $Y$, Nishigori C, Horio T, Miyachi $Y$ (2004) PIG7/LITAF gene mutation and overexpression of its gene product in extramammary Paget's disease. Int J Cancer 111: $218-223$

13. Mortusewicz O, Leonhardt H (2007) XRCC1 and PCNA are loading platforms with distinct kinetic properties and different capacities to respond to multiple DNA lesions. BMC Mol Biol $8: 81$

14. Moser J, Kool H, Giakzidis I, Caldecott K, Mullenders LHF, Fousteri MI et al (2007) Sealing of chromosomal DNA nicks during nucleotide excision repair requires XRCC1 and DNA ligase III $\alpha$ in a cell-cycle-specific manner. Mol Cell 27:311-323

15. Moullan N, Cox DG, Angele S, Romestaing P, Gerard JP, Hall J (2003) Polymorphisms in the DNA repair gene XRCC1, breast cancer risk, and response to radiotherapy. Cancer Epidemiol Biomark Prev 12:1168-1174

16. Nagano T, Kunisada M, Yu X, Masaki T, Nishigori C (2008) Involvement of interleukin-10 promoter polymorphisms in nonmelanoma skin cancers-a case study in non-Caucasian skin cancer patients. Photochemi Photobiol 84:63-66

17. Nelson HH, Kelsey KT, Mott LA, Karagas MR (2002) The XRCC1 Arg399Gln polymorphism, sunburn, and non-melanoma skin cancer: evidence of gene-environment interaction. Cancer Res 62:152-155

18. Nishi M, Yoshida H, Setoyama M, Tashiro M (1994) Immunohistochemical study of c-erb B-2 oncoprotein expression in extramammary Paget's disease. Dermatology 188:100-102

19. Rybicki BA, Conti DV, Moreira A, Cicek M, Casey G, Witte JS (2004) DNA repair gene XRCC1 and XPD polymorphisms and risk of prostate cancer. Cancer Epidemiol Biomark Prev 13: 23-29

20. Thompson LH, Brookman KW, Jones NJ, Allen SA, Carrano AV (1990) Molecular cloning of the human XRCC1 gene, which corrects defective DNA strand break repair and sister chromatid exchange. Mol Cell Biol 10:6160-6171

21. Weiss E, Mamelak AJ, La Morgia S, Wang B, Feliciani C, Tulli A et al (2004) The role of interleukin 10 in the pathogenesis and potential treatment of skin diseases. J Am Acad Dermatol 50: $657-675$ 